\title{
Retrospective View of Two Years of Colposcopy Practice in a Gynecologic Clinic in Cotonou
}

\author{
Mèdessè Véronique Tognifode ${ }^{1}$, Justin Lewis Denakpo², Moufalilou Aboubakar' ${ }^{2}$, \\ Luc Brun ${ }^{3}$, Mathieu Ogoudjobi', Symphorose Lokossou', Angeline Tonato Bagnan², \\ René Xavier Perrin² \\ ${ }^{1}$ University-Affiliated Hospital of the Department of Ouémé-Plateau (CHUD-OP), Porto Novo, Benin \\ ${ }^{2}$ University-Affiliated Hospital for Children and Mothers (CHU-MEL), Cotonou, Benin \\ ${ }^{3}$ Anatomopathology Unit of the University-Affiliated Hospital of the Department of BORGOU (CHUD/B), Parakou, Benin \\ Email: *verofode@yahoo.fr
}

How to cite this paper: Tognifode, M.V., Denakpo, J.L., Aboubakar, M., Brun, L., Ogoudjobi, M., Lokossou, S., Bagnan, A.T. and Perrin, R.X. (2017) Retrospective View of Two Years of Colposcopy Practice in a Gynecologic Clinic in Cotonou. Open Journal of Obstetrics and Gynecology, 7, 226234.

https://doi.org/10.4236/ojog.2017.72024

Received: November 11, 2016

Accepted: February 21, 2017

Published: February 24, 2017

Copyright (c) 2017 by authors and Scientific Research Publishing Inc. This work is licensed under the Creative Commons Attribution International License (CC BY 4.0).

http://creativecommons.org/licenses/by/4.0/

\begin{abstract}
Objective: To analyse the colposcopy results at the Gynaecological Clinic of Houéyiho. Patients and methods: Retrospective, descriptive and analytical studies were conducted by the Clinic of Houeyiho in Cotonou from January 2013 to December 2015. Results. 440 women were received in colposcopy including 251 (57\%) referred by health workers for VIA (Visual Inspection with Acétique Acid)/VILI (Visual Inspection with Lugol's Iodine) abnormalities, forty-seven (47) for abnormal smears (10.7\%), thirty-eight (38) for metrorrhagia (8.6\%). $10 \%$ of cases were mainly concerned with post-therapeutic monitoring (six colposcopies of the vagina fundus after hysterectomy for cervical cancer and four after conization). The average age of patients is 41 years within plus or minus 5 years. Forty (40) cases of Grade 1 Atypical Transformation, twenty-nine (29) cases of Grade 2 Atypical Transformation including two (2) cases of leukoplakia (1 post-conization for CINIII, 1 in a HIV+ patient), ten (10) cases of Grade 1 Atypical Transformation/Grade 2 Atypical Transformation association were recorded. A colposcopy biopsy was performed in 95 patients meaning $21.6 \%$ of patients. Five biopsies were realized for a cervical neoplasia suspicion and were sent to Pasteur Cerba laboratory in France for the sake of efficiency and rapidity of results. In Grade 1 Atypical Transformation, $66.6 \%$ of CIN1 and condylomata plana were noted. Nevertheless, a case of mucinous adenocarcinoma with metaplasia has been discovered in a TAG1 with a 23-year old patient. In Grade 2 Atypical Transformation, the histology reveals $44.4 \%$ of CIN 1 , $40.7 \%$ of severe dysplasia and $11.1 \%$ of carcinomas. Conclusion: The colposcopy may be a good screening method with a good colpo-histology agreement in Cotonou. But it's relatively expensive (20.000 CFA francs) and the reduced number of colposcopists restricts its use in Benin.
\end{abstract}




\section{Keywords}

Colposcopy, Cervical Smear, Precancerous Lesions, Histology, Benin

\section{Introduction}

Each year in sub-Saharan Africa, cervical cancer is diagnosed in 34.8 women out of 100,000 and 22.5 out of 100,000 die because of it, which is ten (10) times more than in North America. In developed countries, its incidence has decreased dramatically since the implementation of a regular cervical-vaginal smear [1]. This difference is explained by delayed diagnosis, linked to the lack of organized screening, lack of equipment and qualified staff, insufficient treatment and the fact that it's far too expensive for people [2]. Cervical cancer screening is based on the realization of the Pap smear, a colposcopy to reach the lesion and guide biopsy and histology for the diagnosis [3] [4].

The colposcopy is accomplished with a colposcope used as a magnifier to show the uterin cervical as and the vagina without preparation then after application of $5 \mathrm{cc}$ of a solution of acetic acid followed by the same quantity of solution of lugol. The pictures of the uterin cervical are got from every stage and recorded. The elementary found lesions are described in report of colposcopy.

Clinic of Houeyiho in Cotonou, committed to the detection of gynecological cancers including cervical cancer, acquired a colposcope in 2012. The main goal of this study is to assess the results of two years of colposcopy practice in this clinic.

\section{Patients, Materials and Methods}

\subsection{Type and Period of Study}

This is a retrospective study carried out in the Clinic of Houéyiho over a twoyear period: from January 1, 2014 to December 31, 2015.

\subsection{Materials}

Patients were examined using a SONY brand colposcope connected to a computer containing a software as represented in the picture below. The camera integrated to the colposcope works with a systematized digital image recording and reporting of basic lesions discovered (Photo 1).

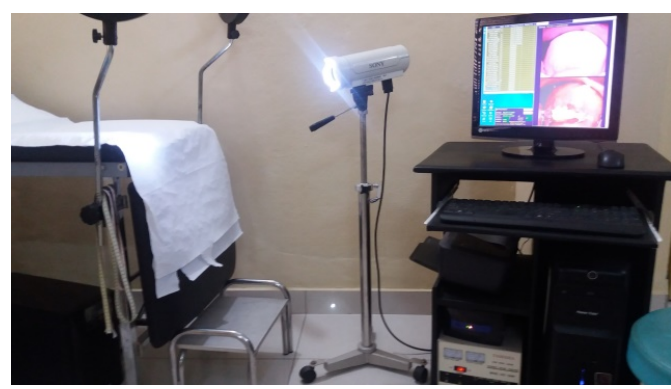

Photo 1. Colposcope connected to a computer. 


\subsection{Patients}

We have proceeded to an exhaustive census of all patients by considering as database the colposcopies recording repertory. Every week, about ten (10) patients were received for colposcopy.

Colposcopy with clichés amounted to 20.000 FCFA.

\subsection{Technical Description}

\subsubsection{Criteria}

- Criteria of inclusion are pathological smear, VIA VILI abnormal, the systématic colposcopyat patients addressed by their doctor after examination of the uterin cervical in the speculum.

- The patients screening macroscopicevocativelesions of the uterin cervical of advanced cancer are excluded from the study.

The method of sampling is constitued by an exhaustive inventory for all files of colposcopy answering our criteria of inclusion/not inclusion.

\subsubsection{Data Collection}

The data collection is developed based on the registers of colposcopy, files of the patientes (cervical examination, result smear or VIA VILI), in the chips of collection/study. In the case of abnormal colposcopy, realized biopsy and the facts samples were sent to pathology centers. (Cotonou, Parakou). At the request of some patients, some were sent to Pasteur Cerba laboratory for a faster delivery deadline of results.

\subsubsection{Variables}

- Socio démographic,

- Private hospital-results smear, VIA VILI,

- Data of the colposcopy,

- Results of anatomy pathology.

\subsubsection{Analysisof Data}

It is made by softwereepi info version 7 .

\subsubsection{Ethical Consideration}

The admnistrative permissions were beforehand obtained and respectable confidentiality.

\section{Results}

During the study period, 440 women were received for colposcopy at clinic Houéyiho in Cotonou. They represented $10 \%$ of patients admitted in gynecology in the clinic.

$43.3 \%$ of patients were either married or concubines and high-level educated in $40.9 \%$ of cases.

They were either administrative officers or traders in most cases.

The socio demographic characteristic of the patients is not much contributive. 
The age distribution of patients is shown in Photo 2.

The average age of patients is 41 years plus or minus 5 years. Two types of colposcopy indications were retained and are presented in Table 1.

In our practice, colposcopy indications are numerous, dominated by: VIA/ VILI abnormalities (57\%), patients who come on their own (21.3\%), metrorrhagia or post-therapeutic monitoring (10.9\%) and abnormal Pap smears (10.7\%). As post-therapeutic monitoring cases, we recoded six (6) vaginal fundus colposcopies after hysterectomy for cervical cancer, and four (4) cases of cone biopsy. The colposcopy main results are shown in Photo 3.

Colposcopy was normal in almost half of the cases (215 cases/440 colposcopy). The most frequent abnormalities were: 50 colpitis $22.2 \%, 40$ immature metaplasia 17.7\%, 39 Grade 1 Atypical Transformation 17.3\%, 35 ectropion 15.5\% and 27 Grade 2 Atypical Transformation 12\%. In five (5) cases, colposcopy has been unsatisfactory because of advanced menopause. A case of cervical ulceration

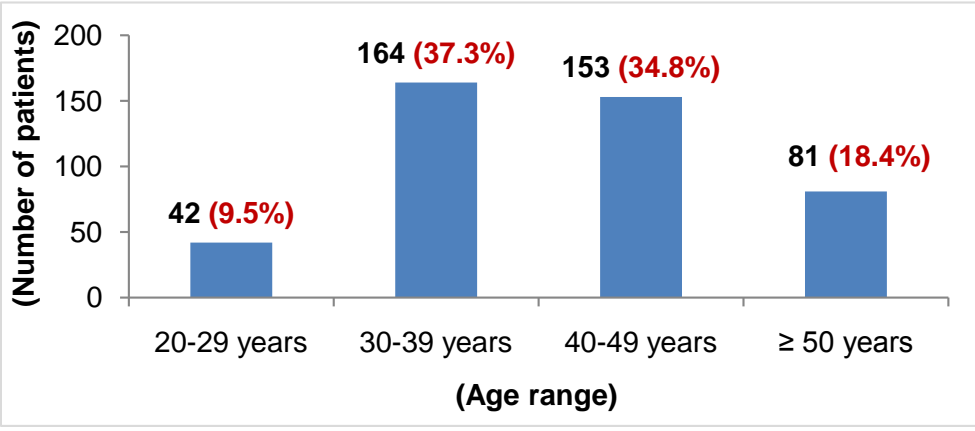

Photo 2. Age distribution of patients.

Table 1. Indications of colposcopies.

\begin{tabular}{llc}
\hline \multicolumn{1}{c}{ Indications } & $\mathbf{n}$ & $\%$ \\
\hline Colposcopy without prior Pap smears & & \\
Patients who come on their own for screening & 94 & 21.3 \\
Patientes sent for abnormal VIA-VILI & 251 & 57 \\
Patients directed for: & 48 & 10.9 \\
Contact metrorrhagia & 18 & 4 \\
Post-menopausalmetrorrhagia & 20 & 4.5 \\
Post-therapeutic monitoring & 10 & 2.3 \\
Colposcopy with abnormal Pap smears & 47 & 10.7 \\
Non-specificinflammatorysmear & 27 & 6.1 \\
ASCUS & 8 & 1.8 \\
ASC-H & 5 & 1.1 \\
Low Grade squamous intraepithelial lesions & 4 & 0.9 \\
High Grade squamous intraepithelial lesions & 2 & 0.45 \\
Presence of koilocytes & 1 & 0.2 \\
Total & 40 & 100 \\
\hline & & \\
\hline
\end{tabular}




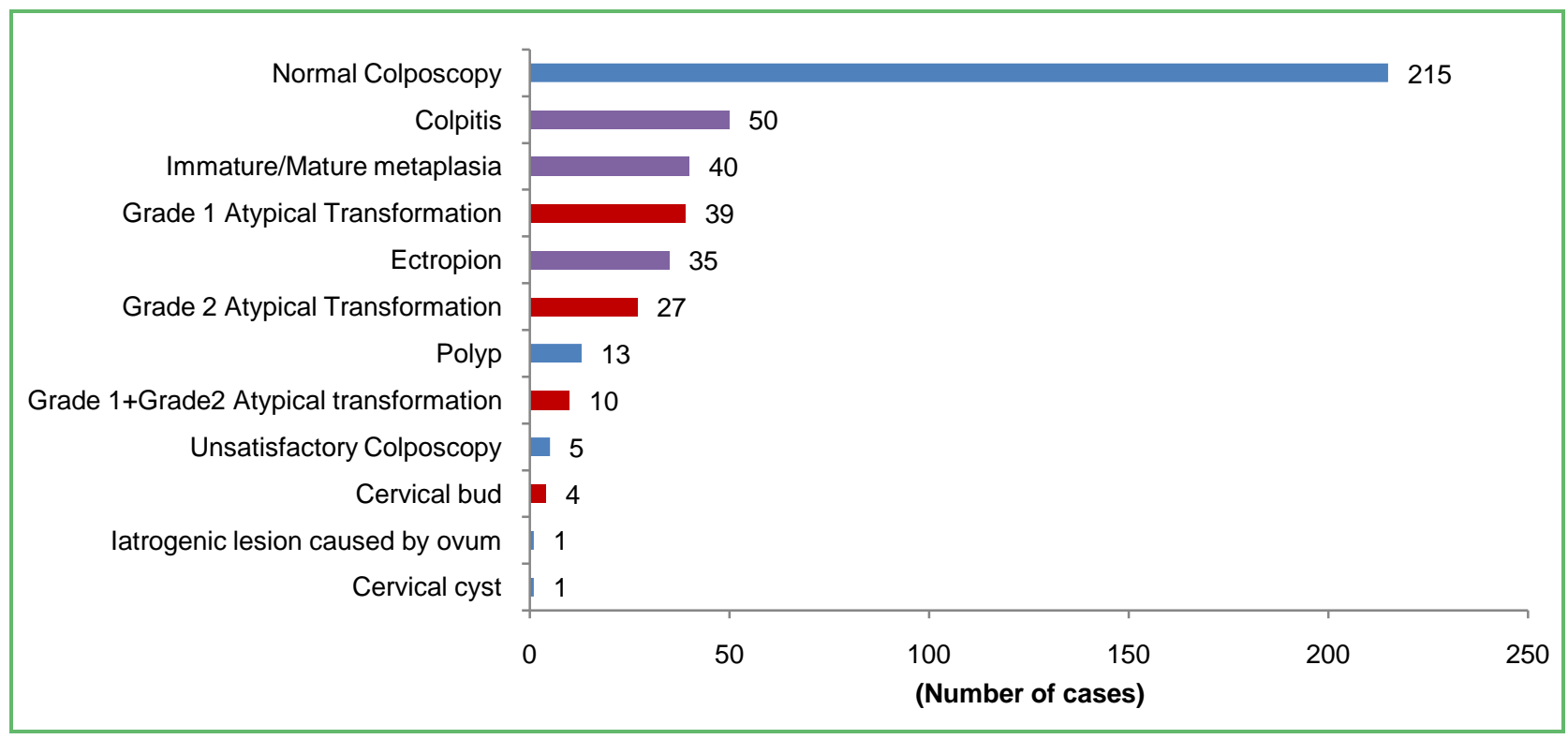

Photo 3. Colposcopy results.

through intravaginal introduction of a plant-based traditional treatment of unknown nature was objectified. Among the Grade 2 Atypical Transformation, we observed two (2) cases of leukoplakia (one after a cone biopsy for CIN III and one in an HIV + patient with an inflammatory smear).

Among the forty-seven (47) cases of abnormal Pap smear, thirty-two (32) colposcopies were normal. The diagnosis of nonspecific inflammatory smear has been noticed on twenty (20) Pap smear (42.5\%) among which, nine (9) Grade 1 Atypical Transformation and six (6) Grade 2 Atypical Transformation, identified in fifteen (15) patients, which required the practice of a biopsy.

A colposcopy biopsy was performed on ninety-five (95) patients in total. Indications were: Grade 2 Atypical Transformation (28.4\%), Grade 1 Atypical Transformation one (1) case + extensive mature metaplasia, Grade 1 Atypical Transformation (41\%), Grade 1 Atypical Transformation + Grade 2 Atypical Transformation (10.5\%), cervical budding (4.2\%), a case of cervical cyst (1\%), and polyps (13.6\%). We were able to collect only forty-nine (49) biopsy results (51.5\%) since the patients have been lost from sight because of the long delivery time of their results.

At the histology, we had recorded eight (8) cases of cervical cancer (16.3\%). It was two (2) squamous cell carcinomas in situ, two (2) adenocarcinomas including one (1) adenocarcinoma in situ, one (1) invasive non-keratinizing squamous cell carcinoma and one moderately differentiated, two (2) invasive squamous cell carcinomas. The age distribution of these lesions allowed us to note four (4) cases of cervical cancer in patients aged over 60 years, three (3) cases in the age range of 40 - 49 years, and one case in a patient aged 23. It was a biopsy for Grade 1 Atypical Transformation + metaplasia which revealed mucinous adenocarcinoma.

The correlation between colposcopy and histology is shown in Table 2 . 
Table 2. Colpo-histologic correlation.

\begin{tabular}{lcccc}
\hline Histology & $\begin{array}{c}\text { TAG } 1 \\
\mathrm{n}(\%)\end{array}$ & $\begin{array}{c}\text { TAG } 2 \\
\mathrm{n}(\%)\end{array}$ & $\begin{array}{c}\text { Cervical } \\
\text { budding } \boldsymbol{n}(\%)\end{array}$ & $\begin{array}{c}\text { TOTAL } \\
\boldsymbol{n}(\%)\end{array}$ \\
\hline Normal & $3(16.6 \%)$ & $1(3.7 \%)$ & 0 & $\mathbf{4}(\mathbf{8 . 1 6 \% )}$ \\
CIN1 and condylomata plana & $12(66.6 \%)$ & $12(44.4 \%)$ & 0 & $\mathbf{2 4}(\mathbf{4 8 . 9 \% )}$ \\
CIN2 & $2(11.1 \%)$ & $8(29.6 \%)$ & 0 & $\mathbf{1 0 ( 2 0 . 4 \% )}$ \\
CIN3 & 0 & $3(11.1 \%)$ & 0 & $\mathbf{3}(6.1 \%)$ \\
Squamous Cell Carcinoma in situ & 0 & $1(3.7 \%)$ & $1(25 \%)$ & $\mathbf{2 ( 4 \% )}$ \\
Invasive SquamousCellCarcinoma & 0 & 0 & $2(50 \%)$ & $\mathbf{2 ( 4 \% )}$ \\
Adenocarcinoma in situ & 0 & $2(7.4 \%)$ & 0 & $\mathbf{2 ( 4 \% )}$ \\
Invasive Adenocarcinoma & $1(5.5 \%)$ & 0 & $1(25 \%)$ & $\mathbf{2 ( 4 \% )}$ \\
Total & $\mathbf{1 8 ( 3 6 . 7 \% )}$ & $\mathbf{2 7 ( 5 5 . 1 \% )}$ & $\mathbf{4 ( 8 . 1 \% )}$ & $\mathbf{4 9 ( 1 0 0 \% )}$ \\
\hline
\end{tabular}

We found twenty-four (24) cases of mild dysplasia (48.9\%), thirteen (13) cases of severe dysplasia (26.5\%) and eight (8) cases of carcinoma (16.3\%). In Grade 1 Atypical Transformation, $66.6 \%$ of CIN 1 was observed against $11.1 \%$ for CIN2. A case of Grade 1 Atypical Transformation has nevertheless proved to be an invasive adenocarcinoma. In Grade 2 Atypical Transformation, $11.1 \%$ of carcinoma, $40.7 \%$ of severe dysplasia and $44.4 \%$ of mild dysplasia were noted. All cases of cervical budding were invasive carcinomas.

Patients with cervical abnormality to colposcopy and/or histology were directed to their referring physician with a letter asking them to transfer the patient to specialized centers to complete, depending on the cases, either a cone biopsy, a cryotherapy or hysterectomy. In some cases, a simple monitoring with resumption of Pap smear or colposcopy has been requested.

\section{Discussion}

Over a two-year period, the practice of colposcopy has a frequency of $10 \%$ in the clinic of Houéyiho in Cotonou. The majority of patients were aged between 30 and 49 years $(72.1 \%)$, which corresponds to the age range found for cervical cancer in a multi-centre study in Guinea [5].

Unlike developed countries, colposcopy practice is recent in African countries. Benin is not immune to this reality. The lack of organized screening, socio-economic conditions of patients, and lack of specialized human resources are some of the reasons for the relatively low frequency of colposcopy in Benin. In developed countries, systematic realization of Pap smears from 25 years old [5] allows the screening of lesions that are colposcopy indications.

In our study, only $10.7 \%$ of patients received, came for an abnormal Pap smear and $57 \%$ for a VIA/VILI abnormality. Some colposcopies were performed in first intention $(32.1 \%)$ without prior smear or VIA/VILI. The difficulties of obtaining a Pap smear and even sometimes VIA/VILI explain the role of first intention colposcopy in our study.

This is also the case in the series of Iloki et al. who also found $39.3 \%$ of col- 
poscopy without prior Pap smear [2]. Abnormal smears are dominated by nonspecific inflammatory smear which nevertheless, reveal Grade 1 Atypical Transformation abnormalities (45\%) and Grade 2 Atypical Transformation abnormalities (30\%) to colposcopy. Ben Hamid et al. found 25\% of Grade 1 Atypical Transformation and $13.57 \%$ of Grade 2 Atypical Transformation on inflammatory smears [6]. Some authors argue about a mismatch which occurs sometimes between the cytological result and the colposcopy. In the literature, cases of negative cytology hiding dysplastic lesions that evolve in silence are actually described [7]. That observation has led the authors to consider for the future, a first intention self-screening through HPV testings, to better target the actual population at risk in connection with oncogenic HPV infection [8].

Given the financial difficulties of the patients in resource-poor country like ours, the IVA-IVL has been proposed as an alternative solution [5] [9] with a very high sensitivity of the VILI according to some study carried out by Fokom-Domque et al. in 2015 [10].

In our series, $48.5 \%$ are normal colposcopies, two times more normal than in the series of Iloki (17.3\%) [2]; presumably because the number of patients received for abnormal smears is lower in our series (10.7\% against $60.7 \%)$. The most frequent abnormalities in our series are: colpitis (22.2\%), metaplasia (17.7\%) and Grade 1 Atypical Transformation (17.3\%). Also in the Brazzaville series about 150 patients received for colposcopy, we rather notice Grade 2 Atypical Transformation (36.7\%) at the head, followed by colpitis (19.3\%) and Grade 1 Atypical Transformation (9.3\%) [2]. All viewable lesions of the sort of Atypical Transformation (Grades 1 and 2), budding, and polyps were subject to a biopsy in our study, that's 95 in total. Five patients among those suspected of invasive cervical neoplasia decided to send their cervical biopsy specimens to Pasteur Cerba laboratory to receive their histological results as quickly as possible (delivery of results in less than two weeks through internet and at double the normal pay rate).

Note that half of an atomopathological results on the spot were not submitted because the patients have been lost from sight. On The histology of 49 results transmitted, $48.9 \%$ of mild dysplasia, $26.5 \%$ of severe dysplasia and $16.3 \%$ of carcinoma have been found. There is a good colpo-histologic correlation in our study. Indeed $66.6 \%$ of Grade 1 Atypical Transformation revealed to be lowgrade lesions at the histology. Similarly nearly half of high-grade lesions were noted in the Grade 2 Atypical Transformation. Colposcopy remains a high sensitivity examination for the screening of pre-cancers [11]. However, in our study, Grade 1 Atypical Transformation lesion was a genuine cervical cancer. It was an invasive mucinous adenocarcinoma in a patient aged 23 which must suggests caution in the interpretation of colposcopy images.

That's why Marchetta proposes that the specificity of colposcopy should be strengthened by a quality charter applicable to all [7] [12] [13]. According to the same author, it's within the high-grade pathology that colposcopy displays her best performance [14]. In sub-Saharan Africa there are not many studies on the 
performance of colposcopy but a study carried out in 2014 in Gabon, showed that the VIA/VILI with colposcope coupled with histology, in case of positive result appears more effective than the Pap smear [15].

Our study was limited by the number of patients lost sight because of long delay of reception of their results because only 49 of results anatomic pathology on 95 realized biopsy (51.5\%) could be recovered.

\section{Conclusions}

The results of our study highlight:

- The importance of colposcopy in the screening of dysplastic lesions of the cervix with a good colpo-histologic correlation,

- The interest in doting with targeted centers in Benin with colposcope, smear and biopsy material but also qualified staff,

- The benefits of reducing the delivery time of an atomopathological results not only for smears but also for cervical biopsies in our country.

\section{References}

[1] Bray, F., Ren, J.S., Masuyer, E. and Ferlay, J. (2008) Global Estimates of Cancer Prevalence for 27 Sites in the Adult Population in 2008. International Journal of Cancer, 132, 1133-1145.

[2] Iloki, L.H., N'dinga, H.G., M’bongo, J.A., Pampandi-Ikourou, A. and Pecko, F. (2012) Twelvemonths of Colposcopy Use at the Brazzaville University Hospital Gynecology Clinic. Médecine et Santé Tropicale, 22, 401-404.

[3] Lansac, J., Lecomte, P. and Marret, H. (2014) The Cervical Cancer. Gynécologie pour le praticien. $8^{\text {ème }}$ éd, Masson, Paris, 75-98.

[4] Boulanger, J.C., Gondry, J. and Verhoest, P. (2011) The Colposcopy. EMCGynécologie, 60-B-10.

[5] Dangou, J.M., Keita, N., Mbaye, K., OMS Bureau Régional Afrique, et al. (2012) Prevention and Management of Cervical Cancer in Guinea. African Health Monitor. Issue \#15.

[6] Ben Hamid, R., Mourali, M., Zghal, D., et al. (2007) Usefulness of Colposcopy in Inflammatory Vagin Frottis. Tunis Medical, 85, 500.

[7] $39^{\text {ème }}$ Congrès National de la Société Française de Colposcopie et de Pathologie cervico-vaginale (SFCPCV). Innovation in Cervical Pathology. http://www.sfcpcv.org

[8] Halfon, P. and Camus, C. (2016) The Auto Sampling Has Been about the Future in the Cervical Cancer Screening in France? 39 ${ }^{\text {ème }}$ Congrès National de la Société Française de Colposcopie et de Pathologie cervico-vaginale.

[9] Mutombo, B.A., Nguma, M.A., Tozin, R.R., Lokomba, B.V., Dikamba, M.N. and Kabongo, M.J.M. (2011) Evaluation of Precancerous Cervical Lesions by Visual Methods (IVA, Colposcopy) at Kinshasa University Hospital. Annales Africaines, 4, No. 4.

[10] Fokom-Domque, J., Combescure, C., Fokom-Defo, V. and Tebeu, P.M. (2015) Performance of Alternative Strategies for Primary Cervical Cancer Screening in SubSahara Africa: Systematic Review and Meta-Analysis of Diagnostic Test Accuracy Studies. BMJ, 351, h3084. https://doi.org/10.1136/bmj.h3084

[11] Liu, A.H., Gold, M.A., Schiffman, M., et al. (2016) Comparison of Colposcopic Im- 
pression Based on Live Colposcopy and Evaluation of Static Digital Images. Journal of Lower Genital Tract Disease, 20, 154-161.

[12] Marchetta, J. and Mergui, J.L. (2016) Evolution de la charte de qualité en colposcopie: Quelle place pour le gynécologue en 2016? 39 ${ }^{\text {ème }}$ Congrès National de la Société Française de Colposcopie et de Pathologie Cervico-Vaginale, 15-16 Janvier 2016. http://www.sfcpcv.org

[13] Meevasana, V., Suwannaruk, K., Chanthasenanont, A., et al. (2014) Is the Correlation between Papanicolaou Smear and Histopathology Results Affected by Time to Colposcopy? Asian Pacific Journal of Cancer Prevention, 15, 1527-3150. https://doi.org/10.7314/APJCP.2014.15.4.1527

[14] Marchetta, J. and Lopes, P. (2004) Diagnostic Performance in the Colposcopy. In: La colposcopie, Masson, Paris, 33-43.

[15] Mpiga, E., Ivanga, M., Koumakpayi, I.H., Engohan-Aloghe, C., Ankely, J.C., Belembaogo, E. and Meye, J.F. (2015) Intérêt de l'inspection visuelle à l'acide acétique et au soluté de Lugol avec colposcope dans le dépistage des lésions du col utérin au Gabon. The Pan African Medical Journal, 22, 165.

https://doi.org/10.11604/pamj.2015.22.165.7038

\section{Scientific Research Publishing}

\section{Submit or recommend next manuscript to SCIRP and we will provide best} service for you:

Accepting pre-submission inquiries through Email, Facebook, LinkedIn, Twitter, etc. A wide selection of journals (inclusive of 9 subjects, more than 200 journals) Providing 24-hour high-quality service User-friendly online submission system Fair and swift peer-review system Efficient typesetting and proofreading procedure Display of the result of downloads and visits, as well as the number of cited articles Maximum dissemination of your research work

Submit your manuscript at: http://papersubmission.scirp.org/ Or contact ojog@scirp.org 